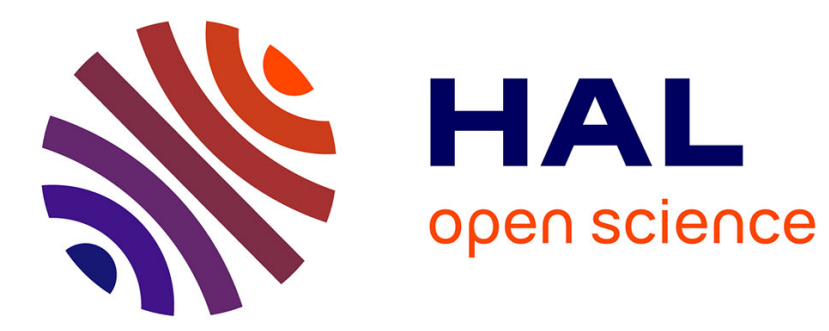

\title{
Music Composition Lessons: the multimodal affordances of technology
}

\author{
Marina Gall, Nick Breeze
}

\section{To cite this version:}

Marina Gall, Nick Breeze. Music Composition Lessons: the multimodal affordances of technology.

Educational Review, 2005, 57 (4), nov 2005, pp.415-433. hal-00190406

\section{HAL Id: hal-00190406 \\ https://telearn.archives-ouvertes.fr/hal-00190406}

Submitted on 23 Nov 2007

HAL is a multi-disciplinary open access archive for the deposit and dissemination of scientific research documents, whether they are published or not. The documents may come from teaching and research institutions in France or abroad, or from public or private research centers.
L'archive ouverte pluridisciplinaire HAL, est destinée au dépôt et à la diffusion de documents scientifiques de niveau recherche, publiés ou non, émanant des établissements d'enseignement et de recherche français ou étrangers, des laboratoires publics ou privés. 


\title{
Music Composition Lessons: the multimodal affordances of technology
}

\author{
MARINA GALL \& NICK BREEZE, Graduate School of Education, \\ University of Bristol, Bristol, UK
}

\begin{abstract}
This article seeks to investigate the multimodal affordances presented by music software and how it can provide new opportunities for students to engage with composition work in the classroom. It aims to broaden the scope of current research into classroom composition using technology, through a study of students' environments and compositional processes as seen from these new perspectives. The authors believe there is a now a need for a reconsideration of the scope of multimodal enquiry in the field of creative music.
\end{abstract}

\section{Introduction}

The multimodal affordances presented by composition software appear to provide new opportunities for students to engage with composition work in the classroom. We provide an account of the processes and outcomes of the InterActive Education research project, ${ }^{1}$ drawing on data from the work of the music team ${ }^{2}$ working within the teaching and learning strand. This explored the ways in which students approached the composition process, through the use of various software programs. Each teacher was asked to consider a composition area of the Music curriculum and plan, develop and teach a Subject Design Initiative (SDI). ${ }^{3}$

The government requires that students aged between 5 and 14 years of age engage with Music composition. So, what characterises composition work in today's Music lessons in English schools? For students aged 7 - 14 (the age of students within our research), this has been typified by work in small groups of between 2 and 6 , often using classroom instruments including keyboards. When using computers, students most commonly work in pairs. Composition briefs provided by the teacher are

\footnotetext{
${ }^{1}$ The overall aims of this project were to understand more about the relationship between ICT and learning and to find ways of using ICT in education to make teaching and learning more effective. Work in English, geography, history, mathematics, modern foreign languages, music and science was carried out with 56 teachers from 10 institutions: 4 primary schools, 5 secondary schools and 1 tertiary college. The research design included five strands each of which looked at ICT in relation to a specific aspect: (i) teaching and learning, (ii) policy and management, (iii) subject cultures, (iv) professional development, and (v) learners' out-of-school uses of technology. Music work discussed in this paper derives from strand (i), teaching and learning. See project website for further information: www.interactiveeducation.ac.uk

${ }^{2}$ The music subject team comprised 3 teachers from 2 primary schools, 5 teachers from 3 secondary schools and 2 teacher educators/researchers (Gall and Breeze). The team worked together over a period of two years both together and in teacher/researcher pairs.

${ }^{3}$ A Subject Design Initiative (SDI) is a unit of work in which the teacher explores the ways in which technology supports learning within the subject.
} 
designed to cover a wide variety of musical genres and styles from different places and times. A group composition may be worked on for 4 to 6 weeks. The National Strategy (2002), with a suggested division of lessons into three sections (launch, main body and plenary) has had implications for music composition. The launch often consists of an outline of the brief, or a recap of work so far and further tasks for the coming lesson; composition takes place in the body of the lesson and the plenary probably involves group performances of work in progress to the whole class, followed by peer and teacher appraisal.

It is easy to explain pragmatic aspects of composition work but the process itself is an elusive one. Research has been carried out into composing in schools but often with a focus on composition products (Sloboda 1985, Swanwick 1988) in the form of recordings and scores. Studies into the process of composition without technology have tended toward a consideration of stages of composition. One of the earliest of these was made by Graham Wallas (1926), who defined four stages as Preparation, Incubation, Illumination, and Verification. These have been influential in shaping academics' views, such as those of Webster, whose complex 'Model of Creative Thinking Process in Music' (2003) attempted to represent the whole process surrounding the composition itself. He suggests that four stages are Preparation, Time Away, Working Through and Verification.

One of the earliest investigations into the process of composition using computers was by Bamberger who researched the decision-making processes in melody writing using a computer-based composition system (cited in Folkestad 1998 p83) with untrained participants. The pupils' ability to think in terms of the sound was apparently shown through the various ways that they moved and ordered pre-recorded blocks of melody. Folkestad suggested that the implementation of music technology influenced the 'what' and the 'how' of music composition (1998, p84).

Our analysis of student composition work is grounded in two distinct theoretical frameworks that we believe combine to enhance our understandings of students' interactions with the process of composition. The first is drawn from multimodality theories related to the changing nature of understanding and meaning-making within an era of expanding forms of design and production, largely brought about by technological change and development (Cope and Kalantzis 2000, Kress 2001) ${ }^{4}$. The second is taken from literature on affordances (Gibson 1979, Norman 1989 \&1993, Trouche 2003, Pea 1993) which suggests that consideration must be given to both the individual's understanding and the objective properties of any focus of human perception. We seek to expand understanding of the changing music composition semiotic landscape brought about by differing composition software packages and the impact that this has on the composition process.

We begin with a brief review of the theories of affordances and multimodality. We then present our methods of working including a short description of the SDIs of four music teachers developed over the course of the project. We then draw on data from the InterActive Education project to illustrate the affordances of composing with music software and to exemplify our emerging conception of the importance of

\footnotetext{
${ }^{4}$ Multimodality is also explored in relation to the English classroom through research by the English team within the same project (Matthewman, 2003 and 2004).
} 
multimodal aspects of the software on the students' working processes. We conclude with an agenda for future research that develops further insight into multimodal aspects of musical composition using technology.

\section{Affordances}

The notion of affordances is generally considered as having originated from the work of Gibson (1979). This centres upon the "perceived and actual" (Pea, in Salomon, 1993, p51) properties of objects, places and living beings. Gibson believes the role of perception to be central: the possibilities of what can be done with something, or someone, are unique to each individual and their situation.

Norman (1988) notes that in our present day technologically driven society, many objects do not have accessibility at the core of their design, thereby restricting perceptions of their possibilities. He notes that affordances provide strong pointers to the way things operate suggesting "Affordances provide strong clues to the operation of things..." (ibid p.9) and that simple things should not require further explanation; their intended purpose should be strongly signalled in their design. Furthermore, he stresses the importance, to would-be designers, of a knowledge of psychology of people as well as of how things work (ibid p.12). Norman further suggests that cultural constraints can limit design possibilities. Importantly for the theory of affordances, he believes that our interpretation of things is based on our past knowledge and experience of our perception of those things. Another key assertion is that technology can present a series of tradeoffs where assets are offset by deficits (1993).

Trouche (2003, p2) describes how deeply tools can impact on human activity. He explains how tools can have important effects on the learning and notes that "tools shape the environment". He goes on to make a distinction between tool and instrument and quotes Verillon and Rabardell (1995, p.80) who posit the claim that an instrument does not exist in itself, but exists when a person has been able to appropriate a tool for him/herself and it has become integrated into his/her activity. He outlines the process of "instrumentalization" where the instrument does not exist in itself but becomes an instrument when the person using it has been able to appropriate it for themselves and has integrated it with their activity. He suggests that the process can go through various stages, including a "transformation" of the tool, sometimes in directions unplanned by the designer. Kress et al, (2001, p.2) add that the individual will shape and re-shape the resources they have available in order to enable their "representations" to match their intentions.

In consideration of the above in relation to the classroom context, Pea (1993) notes that a teacher will experience a good deal of variation in the ways in which a learner will adopt a tool to achieve a given task, dependent upon their previous experience and how they view the possibilities that the tool presents towards achieving their aims. Therefore, "culture and context" have key roles to play.

\section{Multimodality and Music}

The use of new technologies inevitably raises questions about the nature of the interactions that people have with them. In the 1990s, technological change related to the mass media and electronic hypermedia led researchers in the field of literacy to consider other representational modes in their studies of communication and meaning- 
making. In 'Reading Images: The Grammar of Visual Design' Kress and van Leeuwen (1996) suggested the need for new conceptions of communicative practice and new grammars to describe communicative modes other than language. In this work, the authors discussed the widening semiotic landscape particularly in relation to what they perceived as the increasing dominance of visual media.

Cope and Kalantzis (2000, p211) suggest 'audio' as one dimension of five modes of meaning within multimodal texts, the others being linguistic, visual, gestural and spatial. Jewitt also recognises the importance of the aural dimension within computer-mediated learning in school English (Jewitt 2002 \& 2003) but these studies necessarily avoid detailed discussion of music semiotics. Kress (2000, p157) notes that ignoring aspects of all the representational and communicational modes in particular cultures can lead to developing only partial theoretical understandings. Cope and Kalantzis (2000) suggest that modes can 'work together' and that there can be a process of "transduction or transcoding between modes" which Kress (2000) terms "synaesthesia".

A number of researchers have acknowledged the difficulties of exploring the dimensions of sound within multi-modal work. Ong (1982) describes the ephemeral nature of sound: taking the temporal properties away from music leaves the listener with nothing, unlike moving visual media where one can view a still frame.

Nevertheless, there has been recognition of the importance of sound and music. Also comparing sound to visual images within a multimodal text, van Leewen (1999) describes the difficulty of ignoring sound because sound is harder to shut out.

His exploration of music semiotics in "Speech, Music, Sound" (1999) provides a more detailed perspective on music, largely outside the domain of multi-modal texts. He builds on the work of Murray Schafer in his division of sound into three parts - the 'Figure', 'Ground' and 'Field' - which relate to the idea of a foreground, a midground and a background in music (ibid. p15); depending on the 'hierarchy' of these, the listener attends more closely to some more than others. This hierarchy provides the listener with an audio 'perspective'. For example, in traditional jazz, the trumpet or cornet generally plays the melody therefore is the 'Figure' (known, in jazz, as part of the 'front line') and the bass plays a background part i.e. the 'Field'. The use of technology - recording sounds then mixing - allows the designer to make sophisticated changes in relation this perspective. It can subvert this acoustic ordering of sounds so that sounds formerly classified as the 'Field' could become the 'Figure'.

In 'Multimodal Discourse: The Modes and Media of Contemporary Communication' (2001) Kress and van Leeuwen's sketch of a multimodal theory of communication based on an analysis of the specificities and common traits of semiotic modes is important in considering the semiotics of music in the $21^{\text {st }}$ century. Their work also includes discussion of the importance of 'provenance' ('where signs come from' ibid, p10) describing how designs can include signs that originate in other contexts; by including these within the new work, we bring to it associations from the 'other' context. They also suggest that gesture is an important aspect of multimodality (ibid. p54). More recently, Kress (2003, p5) has suggested that new media has the ability to offer users interactivity through the potentials of the different modes of communication and representation. This interactivity can be both interpersonal 
(responding to a "text") and through the medium of "hypertextuality" (where a new relationship is formed between the user and the various "texts").

In this brief exploration of the literature we have attempted to show that no previous work on music semiotics has focussed on technological tools for the production of music or has suggested sound as an important part of the semiotic landscape of multimedia design, studying this from the perspective of music composition.

Through work on the InterActive project, we have seen that a number of the aspects of multimodal design discussed by researchers focussing on literacy and visual texts can be applied to work with music computer software. We have further recognised that multimodal aspects are significant contributors to the affordances of composition with music software.

\section{Methods}

We now turn to a discussion of the empirical work carried out as part of the InterActive Project. Each music teacher developed a Subject Design Initiative (SDI) that focused on embedding ICT into an area of the curriculum; each SDI was a unit of work typically spanning half a term. Its design was informed by theory, researchbased evidence, teacher's craft knowledge and feedback from members of the subject design team. A key aspect of this work was an iterative process that consisted of initial exploration, pilot design, the pilot itself, reflection using the video data by teachers and researchers, modification of the SDI followed by the production and teaching of the final design, to the same year group, a year later.

This paper draws upon data from three SDIs:

Subject Design Initiative 1 (School 1) - Composing in Ternary Form with Dance eJay Pupils aged 10 and 11 were asked to work in pairs to compose a piece of music with the structure - Introduction, A, B, A (with further specifications given for the A and B sections). They worked within the computer lab over a series of 7 weeks using Dance eJay software. This software allows the user to organise pre-recorded musical samples - all of which fit together harmonically - using the computer keyboard. Pupils were also asked to add their own vocal melodies/sounds to their piece. Two staff developed the SDI together but taught different classes within the same year group.

\section{Subject Design Initiative 2 (School 2) - Composing to a Visual Stimulus}

This SDI was created for students aged 12 to 13. They developed compositions inspired by art in the manner of a piece by Mussorgsky, written in 1874 called "Pictures at an Exhibition", which includes sections intended to represent different pictures on show in a gallery. Using Cubasis software, they composed their own sections to given visual stimuli; created within specific musical parameters. Their ideas were input from the MIDI music keyboard; they then selected voices and organised the sounds on the main Arrange page through moving/copying and pasting sections of music. Work took place in the music room. Since there were not sufficient computers for the class to work in pairs, some students worked on the same SDI but with acoustic instruments and keyboards.

Subject Design Initiative 3 (School 3) - Composing Music to an Adventure Film This SDI was designed for students aged 13 to 14 who all worked in pairs at computers, the department having recently been equipped with a music computer 
suite. Students used Cubase VST to underscore a piece of film by arranging musical phrases, provided for them by the teacher in the form of a template. Scenes included a rocket taking off, and a trapped person being rescued from a building overwhelmed by fire.

Data was collected from all SDIs in the form of digital video of classroom interactions, students' composition products as well as interviews with both learners and teachers. In each school, six students were the focus of the research: two 'lowattaining', two 'average' and two 'high-attaining' with a balance of ethnicity and gender. In some schools there were mixed and in others same ability pairs, depending on the work set. Classes within SDIs 1 and 2 were using the software for the first time.

The process was complicated and, like the development of the SDIs, was iterative in that we fully developed our method of collecting sound and pictures over the period of the first year, modifying and re-modifying approaches. There were two main difficulties. The first was to be able to capture the process as shown on the computer screen, whilst also capturing the ways in which the student(s) used the musical keyboard - and to ensure that these were synchronised. The second was to capture the sound from the computer as well as the sound of the students talking.

Our final method involved using two cameras for each pair of students; one focused on the screen the other on the music/computer keyboard. A wide-angled shot was taken with another camera, which captured the whole-class activity, such as teacher introductions and plenaries. A mixer was used to capture the sound from the students' individual microphones as well as the sound from the computer or keyboard, since the students often wore headphones. Video footage was viewed along with the musical products that were saved in files. We also used a screen-save program or discretely named multiple-saves to capture the process of the work.

\section{Discussion}

In the following section, we discuss our observations in relation to identified key issues arising from our theoretical perspectives.

\section{The Affordances of the Interfaces}

A screen shot of student's work using Dance eJay is shown in Fig. 1. Much 'intelligence' is seemingly encoded in this interface and that of Cubasis (see Fig. 2), as it was observed in our study that many details did not need explaining to the students. In fact, the teachers did not provide the pupils with specific information about how to operate the software, but from the start, pupils were able to work with it, competently handling the main features. 


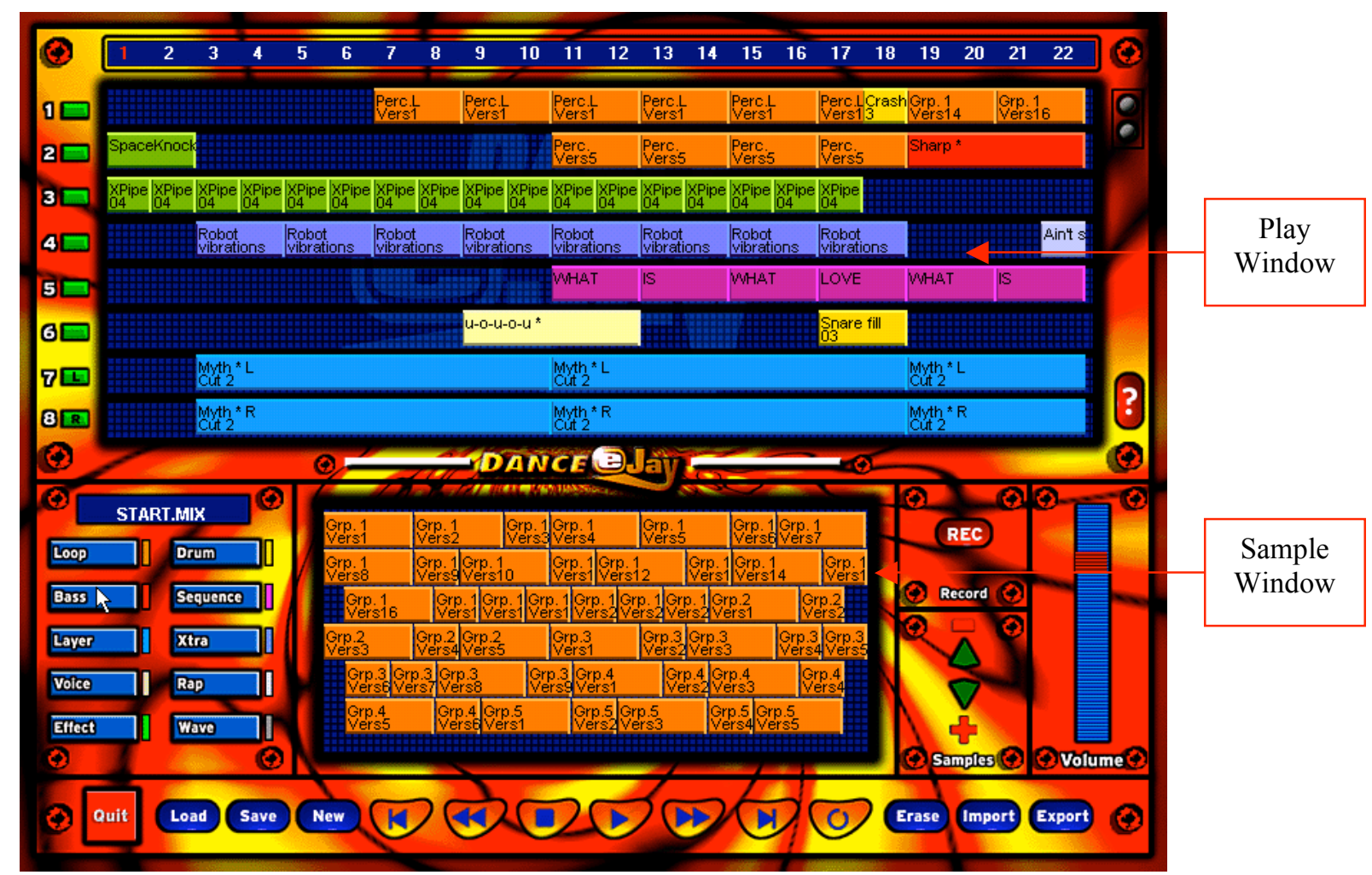

Fig. 1 The Dance eJay Interface

There were a few examples of meanings of symbols being unclear, such as in SDI 2 (See Fig.2), where the meaning of the Left and Right locators on the Transport Bar in Cubasis was unclear and the teacher needed to explain that the Left locator indicated where the recording would start and then demonstrated how it could be set.

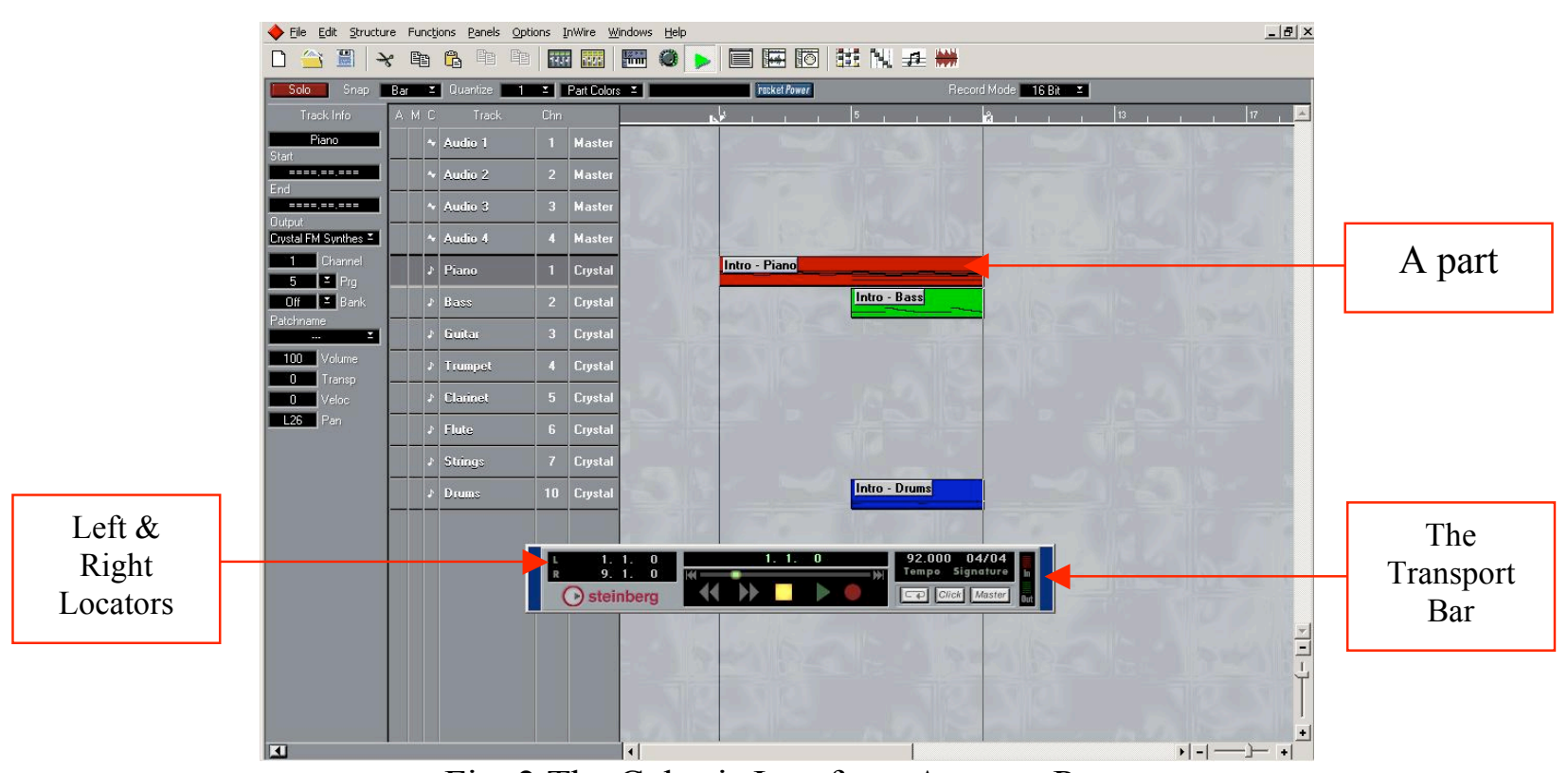

Fig. 2 The Cubasis Interface: Arrange Page

This concurs well with the views of Norman (1988) when he states that successful design should make the purpose of a thing, and how it should be operated, clear. The designs of the eJay and Cubasis interfaces hold much meaning within them and, owing to their use of contemporary "signage", make possibilities clear to the user. 
Some examples of this are: the VCR-style transport controls that are visible in the lower part of both screens; the volume mixer-style slider at the lower right of the eJay screen; the Sample Selection Window (eJay, lower centre) shows the available samples in the chosen Sound Group; the Play Window in eJay shows the arrangement of chosen samples; icons at the top of the screen in Cubasis allow the user to access many functions easily; both interfaces feature the now common format of time represented horizontally and texture vertically. If it is not known what the icon represents, fly-out text displays its purpose when the cursor is held over the object.

As Norman (1988) notes, it is the past experience of things that helps shape their possibilities to the user, and the use of commonly understood symbols, as described above, allows users to apply their prior experiences of similarly fashioned icons to the current task. For example, they know, from using CD players, that by turning the volume slider upwards, the music will get louder. Also the 'Play', 'Fast Forward' and 'Rewind' icons are common to audio-visual technology.

Consider this transcript from SDI 1:
A: We need theme A
B: $\quad$ My word!
A: What? Shall we listen to it first?
B: Are you sure we're doing that bit?
A: $\quad$ See it's got the bottom bit, remember?
(They listen and move to the music)
B: I love that bit!
(They continue listening to the music)
A: $\quad$ This is where um...our theme A starts
B: That's our introduction, isn't it?
A: Yeah and that's where it starts (pointing to the screen)

As can be seen in the screen shots of Dance eJay and Cubasis (Figs. 1 and 2), the spatial arrangement of the parts and samples on the screen clearly is the focus of the work and its multimodal representation as rectangular blocks with names, allows the students to use it as a basis to discuss and develop shared meanings regarding the structure of the emerging pieces.

The rectangular blocks not only represent the sections of music, but in SDI 1, colour was used to help describe the structure and texture of the music:

Teacher: Can you tell me about the theme A. Can someone describe to me the "catchy" bit?

C: $\quad$ It's the orange bit at the top

Teacher: $\quad$ Can you tell me... listen (lots of quiet chatter)...shh.- tell me what sound you hear that's the tune?

(A pupil then sings the melody and the teacher indicates that the first pupil was right: the part he had seen was the "melody")

In another example from the same SDI, a pupil who was classified as 'lowerattaining' by his teacher had prepared the introduction, section A and section B of his piece. He sang along as the music progressed, then stopped singing and chanted in 
time, as if conducting others. He could see the visual make-up of the "B" section and was able to anticipate the start of it:

One, two, three, four. Enter (three bars rest) B,e,e,e, NOW!

One of proposed outcomes was that the students would understand the structure of the piece, and the visual representation afforded by eJay helped the pupils achieve this. Furthermore, the above pupil, in his pre-work interview, had expressed a strong dislike for singing in school (largely because of the style and subject matter of the pieces) and here was observed solo singing a somewhat complicated pattern, with no concern for the many observers who heard him; testament to the motivating nature of the contemporary sounds and rhythms of the software, discussed in more detail below.

Whilst students working on SDIs 2 and 3 commonly chose to work with similar visual support as in eJay (i.e. with blocks of colour representing sound), this Arrange page is only one of the possible representations of the music within Cubasis and Cubase VST. In SDI 3 a student, classified as 'high-attaining' by his teacher, wishing to edit his entered music, decided to use the score editor (See Fig.3). This allowed him to work in a representational form that was familiar to him (stave notation) through the piano lessons that he took outside of school. An additional multimodal aspect of the software is demonstrated here: its ability to represent the same musical MIDI information in different ways.

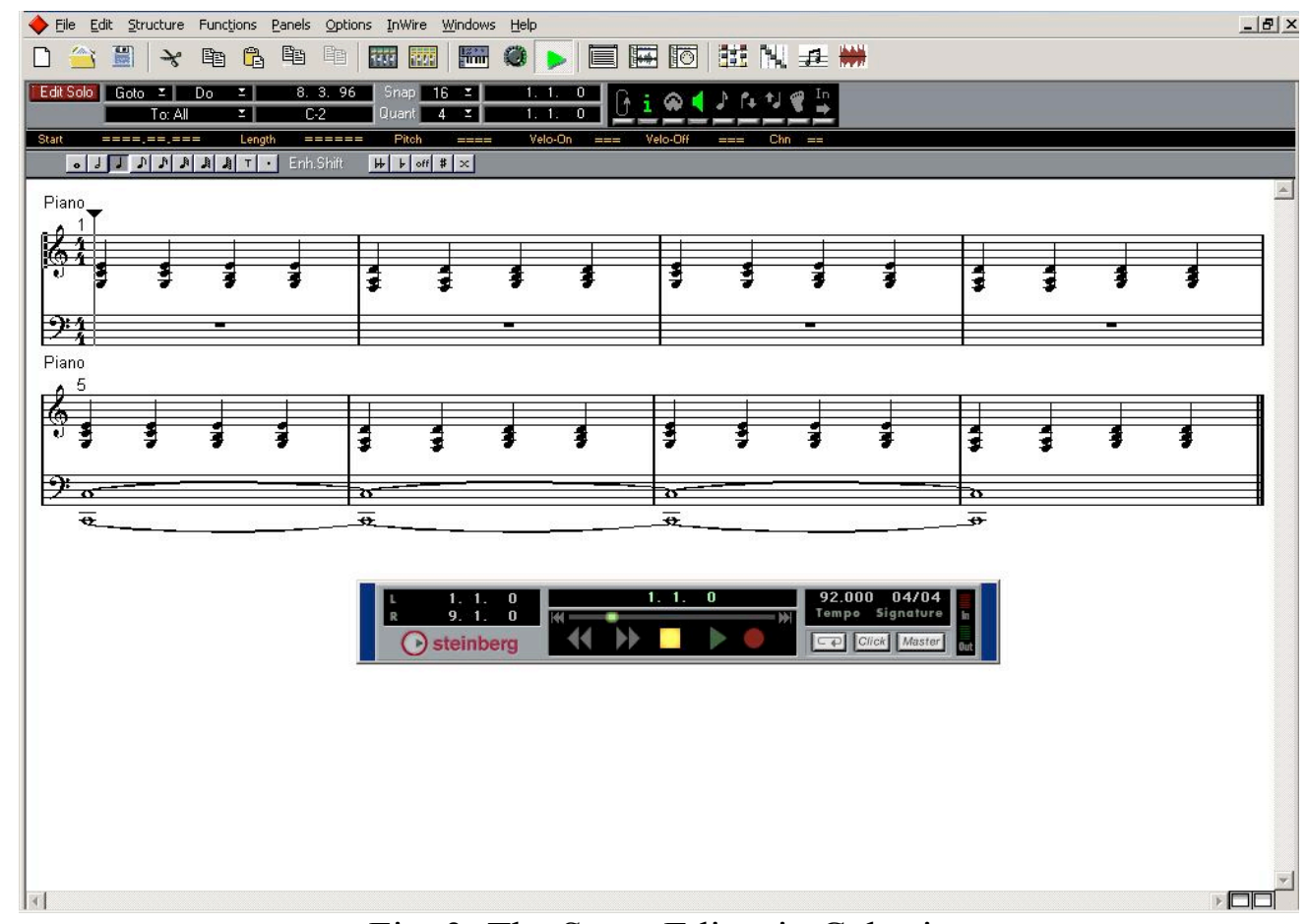

Fig. 3: The Score Editor in Cubasis

Here, the notes can be edited using various techniques. Since the action of doubleclicking the relevant part opens this editor, the student was able to move frequently and quickly between it and the Arrange page. The work of this student is an example of the "instrumentalization" process suggested by Trouche (2003). Here, the teacher had organised the work to be carried out within the Arrange page and the students were not aware that within this work, the music could also be seen as a score; the 
student's partner happened on the score page by chance and the boy then decided to work with this as well, thus changing the use of the computer and the working process as conceived by the teacher. Another explanation could be provided by Kress's notion of "hypertextuality" (2003); the visual depiction of the music through the 'parts' (see Fig.2), allows the students to understand, through interaction, the structure of the music.

A further example of Trouche's "transformation" within "instrumentalization" was evident in the work of two boys in SDI 2 who disregarded the computer click track, invariably used as a useful tool for keeping in time, and played in their music in free time. It seems that perhaps they used this unusual approach because they realised that they did not actually have the skills to play in time with the click track.

The clear layout of the software led one boy in SDI 1 to note:

Sometimes you have to like plan out what you're gonna do but with this it's just kind of, I want to get straight into there because I've got an idea and I don't want to lose it, so you've got a kind of brain wave...

This would appear to indicate that the transparent interface and the lack of need to develop complex technological skills allowed the pupil to compose quickly before creative ideas were lost.

\section{The Affordances of the Computer System: Saving and Reviewing Work}

The ability to save the work is another important affordance of the software. In more "traditional composition" (where groups of students, using instruments and/or voices create music in real time) there is always the risk of forgetting what had been composed in previous lessons; this often happens since music is commonly timetabled only once a week. When asked how the computer had helped the composition, a boy working on SDI 2 replied:

Helped us to remember what we did last week, 'cos otherwise we wouldn't have remembered and so our piece was longer than most other people's that were just doing it at the keyboard by itself.

Whilst a longer piece of music might not necessarily be a good piece, in this SDI, there was an opportunity for students to develop a number of different sections to their piece and this pair had been able to extend their designs further than those not working on computers.

A notable advantage afforded by saving work on networked PCs in SDI 1 was the ability of pairs to listen to other groups' work. Pupils were able to compare their work with others, but in a much more focused manner than audiating it, as they also had the computer screen to see as well as hear what others had done. This transcript, from SDI 1, shows two students at their own PC accessing the work of their neighbours to the right (named F and G), by opening their file. (Italics indicate the names of musical samples):

D: $\quad$ Very Rough Cut It. We can use that in our piece!

E: (Looking towards A) That goes really well! 
D: (Leans over towards B, looking at them. Speaks louder) That goes really well! (10 seconds further on)

E: $\quad$ (Looking at A) Hypa

D: (Looking at E) Definitely!

E: Yeah!

D: (Looking at the screen and talking to the pair to the right) F, we were just thinking about using your things. (Here "your things" means "the same samples as you").

The Computer Tool as a Focus for Collaboration

A key feature observed was the use of the computer screen as a focus for collaboration. The following transcript is from SDI 2, where two students are looking at the computer screen while ' $A$ ' moves the parts around with the mouse:

$\mathrm{H}: \quad$ Move it back to the start a minute .. here it is ... oh no ... stop going up with it ... stop ... look, that is from there ... play a minute ... see what it sounds like. (Music plays) It's from there ... see ... you move that one, that one and then put the church organ over..

I: $\quad$ Move them all separately, that's what you've got to do ... that's the next bit, isn't it?

Because they are focused on the screen, their conversation is necessarily limited to what is essential to add to the action that is being performed with the mouse.

The Affordance of the Software to Meet the Students' Musical Expectations In relation to eJay samples, there is evidence of the balance of the musical components and the positioning of music elements within the sound hierarchy fitting the expectations of this genre of music (dance). Van Leeuwen's hierarchical 'three stage plan' of aural perspective, is echoed in the way eJay structures sound in terms of balance. His description of how in Drum ' $n$ ' Bass, the melody is in the background and the accompaniment is in the foreground (the Figure) and "The rhythm we can dance on becomes the foreground, the text" $(1999, \mathrm{p} 22)$ is apposite. Although the balance of the tracks can be altered in eJay, the students in our study found the default balance of the samples generally met their expectation. Where they wanted to make sounds louder, they 'doubled' them, by placing more than one simultaneously sounding sample in the Play window.

This was seen clearly in the work of J, a 10 year-old pupil, identified by her teacher as having learning difficulties. Discussing one passage of music, with her individual support teacher, she commented:

because that (pointing to the 'Waterworld' sample, which had been placed on 3 tracks, simultaneously) was so quiet I had to double up on it.

From our observations and interviews, a common theme that has emerged is that the technology allows pupils to make music that is culturally relevant to them. In SDI 2, a number of pairs of students on the computers used drum kit sounds within their work; schools rarely own more than one drum kit and therefore, at best, only one group can use this in "traditional composition" activities. Involvement with musical sounds commonly part of pupils' out-of-school listening/dance experiences excited 
those working on SDI 1, some of whom had displayed a lack of interest prior to this work:

K: $\quad$...like if you hear instruments playing on those classical tunes but, like, we're into hip-hop and rock and stuff like that...so it's quite...strange for us, to hear the music we're into...it's new...it's good!

L: $\quad$ You can make your own music (i.e. music that appeals to you)

M: It has a better beat!

The Balance of Affordances - 'Trade-offs'

However, despite many of the beneficial affordances previously mentioned, it was noted that some pupils, identified by the teacher as higher-attaining, found the preprogrammed nature of the provided samples restrictive:

$\mathrm{N}$ : ..it (eJay) sounds very techno and everything and also you can't really get to notes to harmonise (he explained that he changes harmony when using the piano for composing).

O: The basics of getting it to sound OK that was easy...fine tuning it so it sounded... really good was a bit tricky because you might have to cut one bit and add another but then you realise that doesn't work. (i.e. there is no way to shorten or lengthen the samples in this program).

On the other hand, with the Cubasis programme when students had more control over the details of the composition (as in SDI 2), the process was sometimes observed to be more problematic for the students:

...found it difficult to mix the pieces together 'cos they're quite different...

This accords with Norman's notion that technology can present a series of trade-offs (1993). Another aspect of "trade-off" was to be found considering teacher observation of the work in progress; in all SDIs, without being able to hear the sound of the music (i.e. because students were using headphones), the meaning of the dialogue was unclear. In all such instances, this set up an important pedagogical dilemma as to which point the teacher should intervene: s/he had to ask the students to stop work to hear the sound of the music itself, but this necessarily interrupted the students' process of composing and might have inhibited their thoughts since extended pieces of music took some time to be heard. That said, some of the less confident pupils enjoyed the 'enclosed' space for making music and the fact that only their partner generally viewed the work in process:

...you don't get stressed over it and if I do something wrong it doesn't feel bad, because I'm trying it out. (He goes on to explain that one can erase material very quickly.)

A further "trade-off" was highly significant to the teachers' planning of SDI 1. They became aware of the need to clarify to pupils, before they started to use the software, that they had to select the sampled sounds and choose where to place them by making 
decisions based on listening. In the first trial, the teachers realised that there was a strong tendency for pupils to select sounds as a result of an interest in the name of the sample and the pupils themselves seemed to consider the visual aspect of the screen in deciding where to place a new sound as well as - or sometimes instead of - deciding on the merits of the actual musical sound or sound combinations. Furthermore, in a number of cases, in their first lessons, pairs appeared to be placing these unheard samples on the screen to fill up the whole space provided. In a plenary, within lesson 5 , of 8 , reflecting on the composition process, a girl and a boy presented their thoughts:

P: At the beginning, everyone just put random stuff everywhere... they didn't really think about what they were putting, but now they listen to the music more.

Q: $\quad$ Yeh. At the beginning they just put...they didn't leave any spaces and they all just put everything up...

In planning the re-run of the SDI a year later, the teachers were able to pre-empt this random placing of samples and they stressed the importance of the listening within the composition process, thereby steering pupils away from this unmusical approach.

\section{Other Multimodal Affordances}

Multimodal modes other than visual were constantly in play whilst students were composing using technology. In all SDIs the students moved between the range of modes suggested by Cope and Kalantzis (2000 p111). Beginning the project involved listening to the teacher explaining the composition brief and, in some cases, reading the brief as explained on a student worksheet (linguistic: speaking + linguistic: reading). Students discussed their work (linguistic: speaking mode) but, unlike composition with acoustic instruments, once part of the piece had been constructed, this discussion often occurred at the same time as the students listened to the music.

The following transcript shows the work of a high-attaining pair from SDI 3. Students are using headphones during this work):

00. $04 \mathrm{R}$ and $\mathrm{S}$ begin listening to their music. (Music continues throughout the dialogue until 01.28. They also look at the screen throughout.)

$00.20 \mathrm{~S}$ : Yeh that's right

R: That's better!

01.28 (Music stops.)

01.29 R: Right, which other bits (points to screen and keeps pointing)...? We haven't...Can I just hear...? What's there?

S: $\quad$ Yeh, we...There's only two bits in there.

01.43 (R removes finger from screen. They play the music.)

01.44 S: That's it! (Music continues.)

01.50 S: $\quad$ I love that!

01.52 R: Yeh, it's good!

Pointing to the screen, with a finger, to indicate the section/music/sample being discussed, was one of a number of actions that were observed within the gestural mode. Others commonly seen, when students were listening to the music, included 
using the finger to point at the screen, simultaneously moving it up and down in time to the beat; nodding in agreement with the partner whilst facing them and moving in time to the music and smiling at the partner. The latter two were seen most often in situations when students were using headphones, possibly because they were aware that their voice might not be heard above the sound from the computer.

The above example includes the timing in seconds and minutes to show the considerable time students spent listening to the music without speaking (the first here, 16 seconds). Students almost never listened to their music without following the visual design on the screen except when they were speaking or gesturing to their partner, or designing and playing in a part through the music keyboard. Thus the composition process appeared to rely on a synthesis of visual and aural stimuli, arguably an example of what Kress (2000) terms "synaesthesia".

Experimentation on the musical keyboard is a mode that hitherto has not been mentioned in multimodal discourse but is crucial to the process of music composition with technology. In SDI 3, when a higher attaining boy was creating his own ideas, he experimented on the music keyboard, sometimes separately from the computer work and sometimes in sync with it. The boy, a confident keyboard player, relied upon his aural sense when playing in sync with the music from the computer, with his gaze fixed on the keyboard. This was not the case when pupils involved in SDI 1 inputted their own vocal melodies/raps. They continued using the screen as the focus, despite the fact that there was no musical need for this. It is quite possible that, here, the spatial set-up of the classroom had a bearing on this: the pupils worked within a computer room where the workstations were placed around the edge of the room, with little space between each.

Another changing dimension of music composition using technology is the possibility of including film on the computer screen at the same time as the music. As in SDI 3, this allows for more constructive approach to composing music to fit closely with the visuals. Prior to this, students have either been asked to note the timings to changing scenes and actions and then to create music to within this time line or the teacher has run a film through a projector and the students have created music as best they could in real time. This technological affordance allows individuals or groups at the computer to take control of own time for composing.

\section{Further Reflections}

The use of an artefact such as a computer is ... a prerequisite for new ways of creating music...(Folkestad 1999, p83)

Work within the InterActive project has allowed us to begin thinking about two separate but also interrelated aspects of music technology for composition: the affordances of music technology software and multimodality in relation to the computer itself and the processes involved in using it. What is clear is that technology opens up a very different kind of access to the composition process, one which some researchers have referred to as the "democratisation" of music (Folkestad 1998, Goddard 1999, Airy and Parr 2001). Students from all three SDIs were very 
positive about what was, to all of them, a new way of working ${ }^{5}$ and were able to articulate ways in which composing with a computer made the process more egalitarian:

SDI 1 To compose on a traditional instrument you need to be able to play it or have knowledge of music but anyone who can hear can compose on eJay...

SDI 2 Instead of using your brain more you've got to listen to what you are doing, what you're gonna put in your texture.

SDI 3 ...I don't really have the knowledge of loads of different instruments to work (them) together...

Considering the multimodal aspects inherent in the music software itself, we recognise that further research is required to gain insight into how students work within these different modes. In our studies of work with Cubasis and Cubase VST, students were only made aware of the Arrange and score windows. There are three others - the key, list and drum editors, which allow for different manipulation of sounds and which differ visually. Students with more experience of the software are likely to work within a number or all of these windows and, in itself, a study of the movement between the different interfaces and the implications for the composing process would open up new ground.

As part of the process of composing, gesture has always been important in professional group improvisations, for example within jazz, and in student group composition. Our data suggests that the change of visual focus from the group of composers themselves to a computer screen and the use of headphones, which to some extent blocks the student voices, results in new uses of gesture. We hope to analyse further some of our data from the InterActive project, to promote a deeper understanding of this mode in relation to group composition with a computer.

Indeed, we see the need for further exploration of multimodal enquiry in the field of music, particularly in relation to music and technology, as vital, given that music plays such an important role in the lives of the current generation of young people (Tarrant, North and Hargeaves 2001). Recent changes in public music exams in England (Edexcel 2002, OCR 2002a) now allow for investigation of multimodal forms including film music and adverts and the exploration of music is an essential part of Media Studies (Edexcel 2005, OCR 2002b) yet we have limited capacity to discuss music, because sound is such an under-explored semiotic terrain.

Furthermore, despite the rise in importance of music video, where creation of the sound precedes still or moving images, multimodal creative projects in schools rarely begin with the consideration or creation of music:

you compose music after, generally...it's very rare that music comes first... (Ellis and Long 2004 p20)

\footnotetext{
${ }^{5}$ In SDI 3, the students had used Cubase VST before, but not within a multi-media context.
} 
This was also noted in the work of Matthewman (2004), one of the English researchers within our InterActive project; in the context of a literacy lesson, where students were asked to create a multimedia presentation promoting the school's English department to be shown at an open evening for Year 6 pupils and their parents, the audio mode was the least well developed.

Alongside research we would support the development of pedagogical practices within multimodal contexts which raise the status of music as a unique and important mode.

\section{Acknowledgement}

This work is based on the work of the project "InterActive Education: Teaching and Learning in the Information Age". This is a four-year research and development project funded from December 2000 until August 2004 by the UK Economic and Social Research Council (ref; L139251060) as part of Phase II of the Teaching and Learning Research Programme (see http://www.tlrp.org). The project is directed by Rosamund Sutherland (University of Bristol) and co-directed by Susan Robertson (University of Bristol) and Peter John (University of Plymouth). We would like to record our formal thanks to the music teachers who participated in the project.

\section{REFERENCES}

AIRY, S. \& PARR, J.M. (2001) MIDI, Music and Me: Pupils perspectives on composing with MIDI, Music Education Research, 3:1, pp.41-49.

BAMBERGER, J. (1977). In search of a tune, in D. Perkins and B. Leondar (Eds.) The arts and cognition, (Baltimore, Johns Hopkins Press, pp. 284-319).

BERA Music Education Review Group (2001) Mapping Music Education Research in the UK, (Southwell, British Educational Research Association).

BURNARD, P. \& YOUNKER, B. M. (2002) Mapping Pathways: fostering creativity in composition, in Music Education Research, 4:2 pp. 245-261.

COPE, B.and KALANTZIS, M. (2000) Designs for Social Futures, in COPE, B. \& KALANTZIS, M. (Eds.) Multiliteracies: Literacy Learning and the Design of Social Futures, (London/New York, Routledge pp. 203-234).

DEPARTMENT FOR EDUCATION AND SKILLS (DfES) (2002) Designing the Key Stage 3 Curriculum, (London, DfES Publications).

EDEXCEL, (2002) Specification: Edexcel Advanced Subsidiary GCE in Music (8501) / Edexcel Advanced Subsidiary GCE in Music (9501), (London, Edexcel Foundation).

EDEXCEL (2005) GCE Edexcel Advanced Subsidiary GCE in Media:

Communication and Production (Single Award) (8771) / Edexcel Advanced GCE in Media: Communication and Production (Single Award) (9771), (London: Edexcel Foundation). 
ELLIS, V. (2004) 'Negotiating contrad(ICT)tions: teachers and students making multi-media in school'. Technology, Pedagogy and Education, 13:1, pp11-28.

FOLKESTAD, G. (1998) Compositional Strategies in Computer-Based MusicMaking, in British Journal of Music Education 15:1, pp. 83-97.

GIBSON, J. (1979) The Ecological Approach to Visual Perception (Houghton Mifflin, Boston USA).

GODDARD, R. (1999) Technology in Music Teacher Education: An Evolving Philosophy, in Technological Directions in Music Lessons (Ejournal).

JEWITT, C. (2002) 'The Move From Page to Screen: the multimodal reshaping of school English'. Visual Communication, June 2002; 1: pp171 - 195.

JEWITT, C. (2003) 'Re-thinking assessment: multimodality, literacy and computermediated learning'. Assessment in Education, 10:1, pp83- 102.

KRATUS, J. (1985) The use of melodic and rhythmic motives in the original songs of children aged 5 to 13, in Contributions to Music Education, 12, pp1-8.

KRATUS, J. (1989) A time analysis of the compositional processes used by children aged seven to eleven, in Journal of Research in Music Education, 37 (1), 5-20.

KRESS, G. \& VAN LEEUWEN, T. (1996) Multimodal Discourse: The Modes and Media of Contemporary Communication, (London, Arnold).

KRESS, G. (2000) 'Design and tranformation: theories of meaning' in Cope, B. \& Kalantzis, M. (eds.) Multiliteracies: Literacy Learning and the Design of Social Futures, (London/New York, Routledge pp. 153-161).

KRESS, G., JEWITT, C., OGBORN, J. \& TSATSARELIS, C. (2001) Multimodal teaching and learning: the rhetorics of the science classroom (London, Continuum).

KRESS, G. (2003) Literacy in the New Media Age (Abingdon, Routledge).

MATTHEWMAN, S., BLIGHT, A. \& DAVIES, C. (2004) What Does Multimodality Mean for English? Creative Tensions in Teaching New Texts and New Literacies, in Education Communication and Information, 4:1 pp. 153-176.

MATTHEWMAN, S., \& TRIGGS, P. (2004) 'Obsessive Compulsive Font Disorder': The challenge of supporting pupils writing with the computer, in Computers \& Education, 43:1-2 pp. 125-135.

NORMAN, D. A. (1988) The Design of Everyday Things (MIT Press, Cambridge MA).

NORMAN, D. A. (1993) Things that make us smart (Perseus Books, Cambridge MA). 
OCR (2002a) OCR Advanced Subsidiary GCE in Music (3872) / OCR Advanced GCE in Music (7872), (Oxford, Cambridge and RSA Examinations, Cambridge).

OCR (2002b) OCR Advanced Subsidiary GCE in Media Studies (3860) / OCR Advanced GCE in Media Studies (7860), (Cambridge and RSA Examinations, Cambridge).

ONG, W. (1982) Orality and Literacy - The Technologizing of the Word, (London, Methuen).

PEA, R. (1993) Practices of distributed intelligence and designs for education, in G. Salomon, ed. Distributed cognition: Psychological and educational considerations. (Cambridge, CUP pp47-87).

SLOBODA, J. (1985) The Musical Mind: The Cognitive Psychology of Music (Oxford, OUP).

SWANWICK, K. (1988) Music Mind and Education (London, Routledge).

TARRANT, M., NORTH, A. \& HARGREAVES, D.J. (2001) Social Categorization, Self-esteem, and the Estimated Musical Preferences of Male Adolescents, in Journal of Social Psychology, 141:5, pp. 565-581.

TROUCHE, L. (2003). Managing the Complexity of Human/Machine Interaction in a ComputerBased Learning Environment (CBLE): Guiding Student's Process Command Through Instrumental Orchestrations. Paper presented at The Third CAME Symposium: Learning in a CAS Environment: Mind-Machine Interaction, Curriculum \& Assessment (Reims-France, 23 - 24 June 2003).

TURKLE, S. (1984) The Second Self: Computers and the Human Spirit, (New York, Simon \& Schuster).

VAN LEEUWEN, T. (1999) Speech, Music, Sound. (Basingstoke/London, Macmillan).

VERILLON, P. \& RABARDEL, P. (1995) Cognition and artefacts: A contribution to the study of thought in relation to instrument activity, European Journal of Psychology in Education 9:3, pp.77-101.

WALLAS, G. (1926) The Art of Thought (New York, Harcourt Brace).

WEBSTER, P. (2003) Model of Creative Thinking Process. Paper from the Research in Music Education International Conference, Exeter University, UK, 2003. 